УДК $544.46+66.09$

\title{
СОВРЕМЕННЫЕ ДОСТИЖЕНИЯ В МЕХАНОФЕРМЕНТАТИВНОЙ ПЕРЕРАБОТКЕ РАСТИТЕЛЬНОГО СЫРЬЯ
}

\author{
(C) А.Л. Бычков", О.И. Ломовский
}

Институт химии твердого тела и механохимии СО РАН, ул. Кутателадзе, 18, Новосибирск, 630128 (Россия), e-mail: bychkov.a.l@gmail.com

В работе проводится обзор современных опубликованных данных по тематике, посвященной механически активированным процессам переработки растительного сырья. Приведены примеры физико-химических процессов, протекающих при механическом воздействии на индивидуальные вещества и материалы природного происхождения. Показано, что механохимическая обработка позволяет увеличивать реакционную способность веществ, входящих в состав растительного сырья, благодаря увеличению удельной площади поверхности (в том числе площади, «пригодной» для взаимодействия с реагентами, в частности с ферментами), снижению кристалличности целлюлозы и общему разупорядочению супрамолекулярной структуры клеточных стенок. Использование механохимической обработки растительного сырья совместно с ферментами позволяет получать реакционноспособные механокомпозиты, в которых молекулы реагентов равномерно распределены по субстрату недиффузионным способом (механически). Последующие химические реакции с участием данных механокомпозитов протекают эффективнее благодаря уменьшению диффузионных путей и повышению стабильности целевых веществ или ферментов (в случае биотехнологических процессов), а экстракция продуктов протекает более полно. Экономическая эффективность, часто являющаяся лимитирующим фактором внедрения новых технологий, включающих в качестве одной или нескольких стадий измельчение или механическую активацию, определяется затратами на механическую обработку.

Ключевые слова: растительное сырье, механохимия, структура, разупорядочение, дефектность, переработка, технология.

Исследование выполнено за счет гранта Российского научного фонда (проект № 16-13-10200).

\section{Введение}

Направления, связанные с вторичным использованием в химической технологии возобновляемых и невостребованных видов сырья, активно развиваются в последние годы [1-7]. В частности в сфере получения биоэтанола происходит повсеместная замена пищевого сырья на непищевое [8-13]. Наиболее перспективными с этой точки зрения являются отходы сельскохозяйственного производства (солома злаковых, гроздья масличных пальм, подсолнечная шелуха) и растения, имеющие высокую скорость роста и обильную зеленую массу, например мискантус [14-18].

Актуальность развития новых видов переработки растительного сырья закреплена на законодательном уровне. Так, в Российской Федерации создана Технологическая платформа «БиоТех2030», направленная на использование возобновляемой биомассы как сырьевой базы химической промышленности и тяжелого органического синтеза. Аналогичная по целям и содержанию программа Green Chemistry принята в США.

Потребность в рентабельных технологиях является движущей силой исследований с целью развития эффективных способов предварительной обработки сырья. Такой способ предварительной обработки должен сочетать в себе высокую степень активации основных компонентов биомассы, образование малого

Бычков Алексей Леонидович - кандидат химических наук, старший научный сотрудник, e-mail: bychkov.a.1@gmail.com; bychkov_a@solid.nsc.ru Ломовский Олег Иванович - доктор химических наук, профессор, заместитель директора, e-mail: lomov@solid.nsc.ru количества побочных продуктов и низкий расход реагентов при последующих процедурах химической или биотехнологической переработки.

Примеры общепринятых способов предварительной обработки включены в обзоры [19-21]:

\footnotetext{
* Автор, с которым следует вести переписку.
} 
- растворение химическими реагентами или органическими растворителями;

- обработка паром, паровзрывная обработка;

- автогидролиз;

- механическая предобработка;

- ультразвуковая предобработка;

- микроволновое облучение;

- облучение электронами;

- гамма-облучение.

Во всех способах используется дополнительная энергия в виде пара, механического воздействия, излучения. Количество и стоимость этой энергии определяет эффективность предварительной обработки. Иногда для увеличения скоростей процесса и выхода целевых компонентов применяют один или несколько видов предварительной обработки $[22,23]$.

Действие предварительной механической обработки на лигноцеллюлозное сырье обычно объясняют диспергированием обрабатываемого материала и значительным увеличением поверхности раздела твердой и жидкой фаз, на которой протекают последующие гетерогенные процессы в растворах. Большую роль в активации отводят также аморфизации кристаллической целлюлозы, что приводит к существенному увеличению выхода, например при реакции ферментативного гидролиза целлюлозы.

В ряде случаев при механической обработке осуществляется разделение композитного лигноцеллюлозного материала на доступные для реагентов участки из лигнина, гемицеллюлозы и целлюлозы. Совершенствуются методы, позволяющие вводить ферменты в лигноцеллюлозный субстрат, механически распределять молекулы фермента в матрице субстрата, чего невозможно достичь, используя водные растворы фермента $[24,25]$.

С технической точки зрения механическая предобработка признана одним из эффективных методов изменения физико-химических свойств твердых фаз. Поэтому ее применение для предварительной обработки (активации) природных субстратов представляется перспективным подходом.

При разработке механохимических технологий учитывают, что приложенное к твердому телу механическое напряжение может релаксировать по нескольким каналам - главным образом, на образование новой поверхности, на образование дефектов кристаллической и супрамолекулярной структуры, разрыв Ван-дер-Вальсовых и даже ковалентных связей. Эти процессы приводят к увеличению свободной энергии твердого тела, в результате чего повышается его реакционная способность, характеризующаяся повышенными скоростями и выходами последующих реакций.

\section{Основы механохимических методов воздействия на вещества и материаль}

На сегодняшний день существует ряд терминов, подразумевающих приложение механического воздействия к твердым телам. В самом общем случае, когда нет детальной информации о природе протекающих в твердом теле процессов, употребляют термин «механическое воздействие». Уменьшение размеров частиц обрабатываемых материалов, также проводимое без детального изучения физико-химических процессов, называют «измельчением».

Применительно к гетерогенным системам, которые имеют сложный фазовый состав и состоят из множества компонентов, реагирующих в процессе обработки, используют термин «механохимическая обработка». Механохимическая обработка, как и механическая активация, приводит к устойчивым изменениям физико-химических свойств системы. Повышение реакционной способности, как правило, затрагивает большинство фаз и компонентов системы [26, 27].

Существуют более частные термины, например «механоферментативная обработка», представляющая собой механохимическую обработку с участием ферментов либо ферментативный гидролиз с участием предварительно механоактивированного субстрата [28]. Данный вид воздействия может применяться по отношению к растительному и другому биовозобновляемому сырью, природным полимерам и органическим материалам. Механоферментативную обработку проводят с целью увеличения реакционной способности субстрата, возможно также протекание химических реакций, катализируемых ферментами, непосредственно в момент обработки.

В ряде случаев $[29,30]$ при механохимической обработке гетерогенных смесей образуются механокомпозиты, представляющие собой систему, физико-химические свойства которой значительно отличают- 
ся от исходной смеси и определяются существенным изменением морфологии компонентов, прежде всего наличием развитой границы раздела фаз с выраженным межфазным поверхностным взаимодействием. Площадь границ раздела фаз в механокомпозитах может в 100-1000 раз превышать площадь контактов частиц фаз с такими же размерами в смесях, полученных в результате простого механического смешения порошков. Межфазная граница обладает физико-химическими характеристиками, которые не свойственны ни одному из исходных компонентов и индивидуальных фаз.

Реакционная способность твердых фаз ограничена малой подвижностью компонентов, из которых эти фазы состоят. Под действием интенсивных механических нагрузок компоненты перемешиваются, размещаются в непосредственной близости друг от друга таким образом, что диффузионные пути резко сокращаются. Механическая обработка смеси твердых фаз может вызывать повышение подвижности компонентов в момент обработки за счет разупорядочения кристаллической структуры твердых фаз и перемещения фрагментов структуры. Твердые компоненты могут накапливать дефекты и аморфизоваться, в результате этого повышается реакционная способность как компонентов, так и системы в целом. В данном случае речь идет о «механической активации, mechanical activation» - ускорении последующих физикохимических процессов с участием продукта механической обработки. Механически активированное твердое тело отличается тем, что процесс его деформации и физико-химические последствия деформации разделены временем, недостаточным для завершения релаксационных процессов [27, 31].

Механическая активация и следующий за ней химический процесс с участием жидкой фазы, например гидролиз, экстракция, химическое взаимодействие твердых компонентов вследствие полного или частичного растворения в жидкой фазе, могут быть совмещены. Показано, что при механической обработке системы твердое тело - жидкость наблюдаются инициирование и ускорение различных химических превращений. Протеканию таких химических реакций способствуют явления, характерные для активации смесей твердых компонентов (увеличение границы раздела фаз, накопление дефектов, аморфизация, повышение свободной энергии). Высокие температуры и давление, возникающие при механической обработке, могут также создавать необычные условия для химических реакций. Интенсивное механическое воздействие на гетерогенные системы, содержащие жидкость, в ряде случаев приводит к возникновению в локальных участках обрабатываемого объема гидротермальных условий и протеканию кавитационных процессов [32].

Для уменьшения затрат на проведение механической активации, обработка твердой смеси может быть остановлена на ранней стадии превращения реагентов, а полное химическое превращение достигается в результате других, менее энергоемких процессов, как правило, с участием жидких фаз.

С экономической точки зрения механическая энергия является «дорогостоящим» типом энергии, и использовать ее необходимо эффективно. К сожалению, создание экономически эффективных механохимических технологий в настоящее время тормозится тем, что нет общей теории, одинаково хорошо и всесторонне описывающей механохимические реакции, часто рассматриваются лишь отдельные аспекты превращений и возможные явления:

- образование активных поверхностных радикалов [33, 34];

- роль межфазовых процессов, увеличение поверхности и связанные с этим размерные эффекты [35];

- гидротермальные химические процессы [32];

- разупорядочение кристаллической структуры и аморфизация;

- образование механокомпозитов [29, 30].

При этом эффективность осуществления механохимических превращений зависит не только от химических свойств реагентов, но и от их механических свойств. Проведение механохимических процессов, в которых участвуют «мягкие» вещества и материалы, требует небольших затрат энергии [36]. Твердость органических веществ, как синтетического, так и растительного происхождения, обычно гораздо ниже, чем неорганических. Механохимические реакции, протекающие в органических системах, имеют во много раз больший энергетический выход, чем в неорганических системах. Показано, что некоторые органические реакции более эффективно проводить в твердой, нежели в жидкой фазе [37-39]. Таким образом, в плане технологического использования наиболее перспективными оказываются механохимические процессы, протекающие с участием органических веществ. 


\section{Механическая активация растительного сырья}

В отличие от хорошо изученных к настоящему времени процессов переработки пищевого сырья (крахмал и низкомолекулярные сахара), задача переработки и утилизации непищевого растительного сырья осложняется многоуровневым структурированием исходного материала «органы - ткани - клеточные стенки - клетки».

В приложении к экстракционным процессам механохимические методы помогают решать проблему структурирования материала путем разрушения тканей и клеток на более мелкие фрагменты. Получение тонко измельченного продукта, а в ряде случаев и проведение механохимической реакции, позволяет значительно снизить вклад диффузии растворителя и экстрагируемых веществ сквозь материал, повысить эффективность и селективность извлечения [25, 40-44]. Так, механохимическая обработка с твердыми основаниями приводит к образованию солей тритерпеновых кислот непосредственно в матрице растительного сырья, а выход экстракции целевых компонентов увеличивается в 1,5-2 раза [43].

Основными факторами, ответственными за реакционную способность растительного сырья, считают химический состав лигноцеллюлозы, доступную для последующей реакции площадь поверхности частиц, степень кристалличности целлюлозы $[11,45,46]$. Сведения о более тонких супрамолекулярных изменениях клеточных стенок, также отвечающих за наблюдаемые эффекты, носят отрывочный характер.

В первую очередь результативность ферментативных процессов определяется содержанием в растительном сырье лигнина, который необратимо адсорбирует ферменты из реакционной смеси. Увеличение количества ферментов, требующихся для конверсии определенного количества целлюлозы в глюкозу, вследствие потерь фермента на адсорбцию лигнином вносит существенные коррективы в экономическую эффективность процессов получения биоэтанола.

Развиваемые методы окислительной делигнификации [46-49] зачастую не решают проблему инактивации ферментов из-за того, что примеси продуктов окисления лигнина также взаимодействуют с белками [50].

В связи с этим многие исследователи стараются использовать низколигнифицированное растительное сырье, например пустые грозди масличной пальмы (Empty Fruit Bunches, EFB) с содержанием лигнина $10 \%$ [51]. Для сравнения, солома кукурузы, которой посвящено множество работ, содержит около $20 \%$ лигнина [52].

Однако выбор растительного сырья, основывающийся только на химическом составе, не всегда приводит к ожидаемым результатам. Сравнительные исследования ферментативного гидролиза соломы кукурузы и пустых гроздей масличной пальмы, представленные в [53-55], показали, что однократная механическая активация пустых гроздей масличной пальмы в планетарной мельнице позволяет гидролизовать $35-40 \%$ целлюлозы, что значительно выше выхода для неактивированного сырья. В этих же условиях предварительная механическая обработка соломы кукурузы позволяет гидролизовать до растворимых углеводов 85-90\% целлюлозы. При этом начальная скорость гидролиза механически активированной соломы в 2-3 раза выше, чем при гидролизе исходной соломы. Биомасса пустых гроздей масличной пальмы гораздо трудней подвергается измельчению, целлюлоза аморфизуется слабее, нежели в случае соломы кукурузы.

Одним из дополнительных преимуществ применения механической обработки в биотехнологиях является возможность одновременного разрушения клеточных мембран, на что в других вариантах технологии требуются дополнительные затраты тепловой энергии и реагентов. Высказано предположение [53], что ключевую роль в процессах измельчения и увеличения реакционной способности выбранных объектов играет супрамолекулярная структура клеточных стенок биомассы.

Было показано, что высоколигнифицированные ткани соломы кукурузы при измельчении фрагментируются на частицы размером 40-60 мкм, нарушается их клеточная структура. Клеточные стенки разрушаются по областям, соответствующим локализации лигнина, что может быть обусловлено их хрупкостью. Ультраструктура клеточных стенок частиц, попавших под ударно-сдвиговое воздействие мелющих тел, нарушается: слои целлюлозы расширяются и местами взаимопроникают в диффузные слои лигнингемицеллюлозного матрикса. По-видимому, слои в таких частицах в результате механического воздействия смещаются относительно друг друга. Можно предположить, что полученные частицы обладают высокой реакционной способностью благодаря не только повышению площади доступной поверхности, но и разупорядочению структуры. 
Снижение степени кристалличности (СК) целлюлозы, которым часто принято объяснять [56] увеличение реакционной способности, «работает» лишь для субстратов, не содержащих лигнин. В этом случае скорость процесса обратно пропорциональна степенью кристалличности с коэффициентом около 0,9 [57]. В случае материалов, содержащих лигнин, разупорядочение целлюлозных кристаллитов увеличивает скорость неочевидным образом и вносит вклад преимущественно в суммарный выход реакции [58].

Низколигнифицированные клеточные стенки материала гроздей масличной пальмы при сопоставимых механических воздействиях фрагментируются на частицы 50-100 мкм [53]. При этом наблюдается образование трещин перпендикулярно клеточным стенкам и вдоль транспортных каналов. Фрагментация сырья масличной пальмы не сопровождается видимым нарушением ультраструктуры клеточных стенок. По-видимому, увеличение реакционной способности биомассы пустых гроздей масличной пальмы после интенсивной механической обработки обусловлено главным образом увеличением площади поверхности, а для увеличения значимости вклада от разупорядочения структуры необходимо повышение эффективности механической обработки. Кроме того, для низколигнифицированных материалов можно ожидать протекания рекристаллизации предварительно аморфизованных областей целлюлозы.

Влияние рекристаллизации на реакционную способность целлюлозы хорошо изучено к настоящему времени [59-61]. Показано влияние воды [62], состава растворителя и адсорбции ферментов на поверхности [63], определены тепловые эффекты, обусловливающие перестройку аморфизованных участков в структурированные [64]. Например [65], обработка предварительно аморфизованной хлопковой целлюлозы (степень кристалличности 32\%) раствором ферментов в течение 48 ч приводит к росту степени кристалличности до 76\% (обработка в аналогичных условиях, но без добавления ферментов, увеличивает степень кристалличности до 45\%). Схожие результаты демонстрируют в [66], аморфизованная в течение 40 мин (активатор Retsch MM-2) микрокристаллическая целлюлоза (СК 33\%) в результате однократного увлажнения восстанавливается до степени кристалличности 46\%.

Однако подавляющее большинство работ по изучению рекристаллизации было сделано с использованием в качестве образцов чистой целлюлозы или материалов, содержащих до 90\% (и выше) целлюлозы. Лишь в работе [67] проведены сравнительные исследования и показано, что в материалах, содержащих лигнин, рекристаллизация аморфизованной целлюлозы I в целлюлозу II протекает значительно медленнее.

Присутствие аморфных или кристаллических полимеров также вносит особенности в механохимически активированное извлечение низкомолекулярных биологически активных соединений. Так, компоненты лигноцеллюлозной матрицы (целлюлоза кристаллическая, аморфная), не сохраняющие природную морфологическую структуру, в модельных экспериментах снижают устойчивость сорбированного кверцетина при механическом воздействии. Адсорбция на лигнине дестабилизирует кверцетин в наибольшей степени. В случае углеводных компонентов способность уменьшать устойчивость сорбированного кверцетина в процессе механического воздействия снижается в ряду: кристаллическая целлюлоза > аморфная целлюлоза > гемицеллюлоза [68, 69].

Следующим по значимости параметром, отвечающим за реакционную способность лигноцеллюлозы, является удельная площадь поверхности материала. Известно, что тонкое измельчение сухого растительного сырья позволяет увеличивать скорость начальной (гетерогенной) стадии, например последующего сжигания, экстракции, кислотного или ферментативного гидролиза полимеров, входящих в состав клеточных стенок [11, 54, 55, 70-74].

При этом прямая зависимость между дисперсностью и скоростью процесса наблюдается в случае гетерогенной реакции «твердое - газ», протекающей при сжигании мелкодисперсного лигноцеллюлозного топлива [70, 75-77]. Возможно увеличение интенсивности процессов переноса в несколько раз за счет увеличения реакционной поверхности и снижения энергии активации реакций окисления. Как и в случае с механоактивированными углями [78-81], наилучшие результаты получаются в случае, когда частицы биомассы (топлива) имеют размер в интервале 10-100 мкм. В этих условиях совокупный процесс горения имеет несколько последовательных стадий: испарение воды, пиролиз, горение летучих веществ, горение угольного остатка [76]. Достижение столь тонкого помола в промышленных масштабах в настоящее время является трудной задачей и достигается путем внедрения новых технологий измельчения [82] или предварительной обработкой сырья $[54,83,84]$. Так, прогрев древесных стружек до $300{ }^{\circ} \mathrm{C}$ позволяет благодаря частичному пиролизу получать более мелкодисперсное порошковое топливо (130 мкм против 710 мкм для необработанного сырья) при меньших удельных затратах энергии (23,9 кВт·ч/т против 237,7 кВт·ч/т) [84]. 
В случае, когда реакция протекает на границе «твердое - жидкость», например во время экстракции или гидролиза, удельная площадь поверхности, чаще всего определяемая методом десорбции газов, не коррелирует с начальной скоростью. Исходя из того, что для сорбции молекул ферментов доступны лишь макропоры с диаметром 3-5 нм [85], а десорбцией газов определяются и микропоры, корректно оценивать площадь поверхности с использованием макромолекул, близких по размерам к ферментным глобулам [86-89]. Определенная такими методами удельная площадь поверхности не учитывает микропоры и может служить для прогнозирования скорости начальной гетерогенной стадии (зависимость линейна с коэффициентом корреляции $0,8-0,9)$ [87, 90].

Перечисленные факторы, влияющие на реакционную способность растительного сырья, чаще всего проявляются в комплексе. Например, в способе предварительной обработки, описанном в патенте [91], исходное сырье - траву, солому замачивали в жидкости, отжимали на валках для удаления растворимых веществ и нарезали на мелкие частицы. Специально подобранная V-образная форма валков позволяла не только увеличить площадь поверхности (за счет измельчения материала) и снизить степень кристалличности целлюлозы, но и разупорядочить супрамолекулярную структуру клеточных стенок. Подготовленное таким образом сырье гидролизовалось кислотой при более низких температурах.

Аналогично в [92] предлагается проводить предварительную обработку биомассы в экструдере, обеспечивающем в зоне обработки повышенную температуру и давление. Снижение кристалличности целлюлозы, увеличение площади поверхности, а также частичное плавление и удаление лигнина приводит к тому, что в дальнейшем целлюлоза может превращаться в сахара с минимальным использованием кислоты.

Более тонкое измельчение предлагается использовать авторами в патенте [93]. Солому злаков измельчают на молотковой мельнице до получения частиц с размером 400-800 мкм. После этого расщепляют лигнин с использованием культуры бело-красных грибов и подвергают сахарификации с использованием целлюлазы и ксилоназы. Полученные углеводы ферментируют до этанола. Авторы характеризуют этот способ как дешевый и выгодный, благодаря уменьшению размеров частиц. Удаление лигнина наряду со снижением ингибирующего действия также способствует появлению новой площади целлюлозы и положительно сказывается на эффективности процесса.

Наиболее ярко иллюстрирует преимущества механической активации процесс, предлагаемый авторами [94]. Разупорядочение структуры лигноцеллюлозы приводит к тому, что скорость ферментативного гидролиза до 6 часов остается постоянной (и высокой). После этого, когда аморфный субстрат заканчивается, проводится повторная механическая активация, и реакция возобновляется с прежней интенсивностью (рис.).

Основным препятствием для развития механических методов предобработки лигноцеллюлозы является трудность масштабирования лабораторных разработок и переход к промышленному оборудованию $[95,96]$. Большинство исследований сейчас выполняются в лабораторном масштабе [97, 98] и направлены на сверхтонкий помол сырья [99, 100], достижение максимально возможной реакционной способности целлюлозы [101, 102], что часто не выгодно по энергозатратам [100, 103].

Таким образом, механохимическая обработка позволяет увеличивать реакционную способность веществ, входящих в состав растительного сырья, благодаря увеличению удельной площади поверхности (в том числе площади, «пригодной» для взаимодействия с реагентами, ферментами), снижению кристалличности целлюлозы и общему разупорядочению супрамолекулярной структуры клеточных стенок.

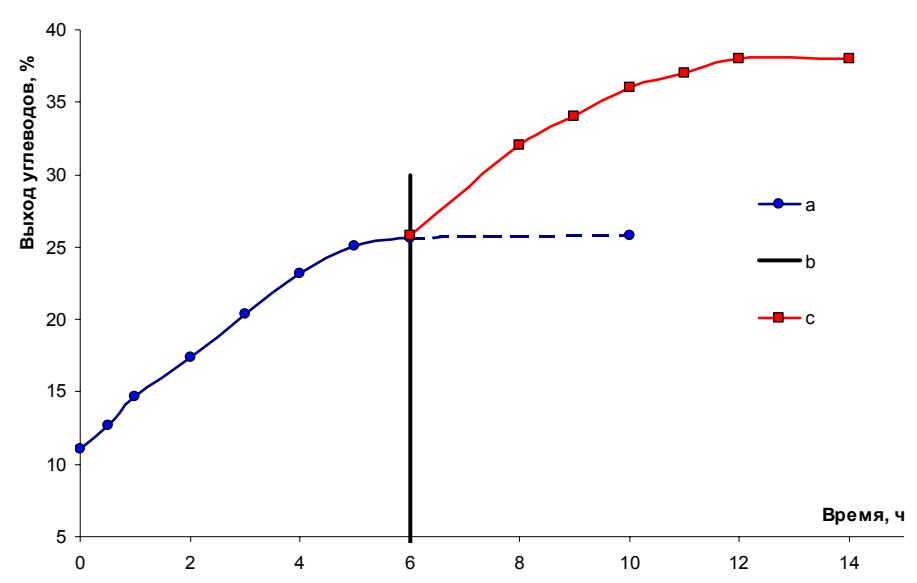

Механически активированный ферментативный гидролиз соломы пшеницы: а - первый цикл гидролиза механически активированного субстрата; b - повторная механическая активация; c - продолжение процесса гидролиза [94] 
Использование механохимической обработки растительного сырья совместно с реагентами позволяет получать реакционноспособные механокомпозиты, в которых молекулы реагентов распределены по поверхности субстрата. Последующие химические реакции с участием данных механокомпозитов протекают эффективнее благодаря уменьшению диффузионных путей и повышению стабильности целевых веществ или ферментов (в случае ферментативных процессов).

Экономическая эффективность технологических процессов, включающих в качестве одной или нескольких стадий измельчение или механическую активацию, определяется затратами на механическую обработку.

\section{Список литературы}

1. Kuznetsov B.N., Chesnokov N.V., Yatsenkova O.V., Sharypov V.I. New methods of heterogeneous catalysis for lignocellulosic biomass conversion to chemicals // Russian Chemical Bulletin. 2013. Vol. 62. N 7. Pp. 1493-1502.

2. Kushnir E.Y., Autlov S.A., Bazarnova N.G. Preparation of microcrystalline cellulose directly from wood under microwave radiation // Russian Journal of Bioorganic Chemistry. 2015. Vol. 41. N 7. Pp. 713-718.

3. Mikhailenko M.A., Shakhtshneider T.P., Drebushchak V.A., Skvortsova G.P., Boldyrev V.V. Influence of mechanical treatment on the properties of betulin, betulin diacetate, and their mixture with water-soluble polymers // Chemistry of Natural Compounds. 2011. Vol. 47. N 2. Pp. 229-233.

4. Селютина О.Ю., Поляков Н.Э., Метелева Е.С., Душкин А.В. Физико-химические подходы к исследованию новых систем доставки лекарств на основе природных полисахаридов // Химия в интересах устойчивого развития. 2015. Т. 23. № 5. С. 549-560.

5. Manaenkov O.V., Filatova A.E., Makeeva O.Y., Kislitsa O.V., Doluda V.Yu., Sidorov A.I., Matveeva V.G., Sul'man E.M. Ru-Containing catalysts on polymer supports for converting cellulose into polyols // Catalysis in Industry. 2014. Vol. 6. N 2. Pp. 150-157.

6. Bazarnova N.G., Markin V.I., Katrakov I.B., Kolosov P.V., Cheprasova M.Y., Kalyuta E.V. Methods of obtaining lignin-carbohydrate compounds from chemically modified plant raw materials // Russian Journal of General Chemistry. 2015. Vol. 82. N 5. Pp. 947-954.

7. Shapolova E.G., Lomovsky O.I. Mechanochemical solubilization of silicon dioxide with polyphenol compounds of plant origin // Russian Journal of Bioorganic Chemistry. 2013. Vol. 39. N 7. Pp. 765-770.

8. Galbe M., Zacchi G. A review of the production of ethanol from softwood // Applied Microbiology and Biotechnology. 2002. Vol. 59. Pp. 618-628.

9. Lynd L.R., Weimer P.J., Zyl W.H., Pretorius I.S. Microbial cellulose utilization: fundamental and biotechnology // Microbiology and Molecular Biology Reviews. 2002. Vol. 66. N 3. Pp. 506-577.

10. Zheng Y., Pan Z., Zhang R. Overview of biomass pretreatment for cellulosic ethanol production // International Journal of Agricultural and Biological Engineering. 2009. Vol. 2. N 3. Pp. 51-68.

11. Taherzadeh M.J., Karimi K. Pretreatment of lignocellulosis wastes to improve ethanol and biogas production: a review // International Journal of Molecular Sciences. 2008. Vol. 9. Pp. 1621-1651.

12. Bai F.W., Anderson W.A., Moo-Young M. Ethanol fermentation technologies from sugar and starch feedstocks // Biotechnology Advances. 2008. Vol. 26. N 1. Pp. 89-105.

13. Скиба Е.А., Будаева В.Д., Макарова Е.И., Павлов И.Н., Золотухин В.Н., Сакович Г.В. Биоэтанол из целлюлозы плодовых оболочек овса // Вестник Казанского технологического университета. 2013. Т. 16. № 22. С. 202-205.

14. Makarova E.I., Budaeva V.V., Skiba E.A., Sakovich G.V. Enzymatic Hydrolysis of celluloses obtained via the hydrothermal processing of Miscanthus and oat hulls // Catalysis in Industry. 2014. Vol. 6. N 1. Pp. 67-71.

15. Sørensen A., Teller P.J., Hilstrøm T., Ahring B.K. Hydrolysis of Miscanthus for bioethanol production using dilute acid presoaking combined with wet explosion pre-treatment and enzymatic treatment // Bioresource Technology. 2008. Vol. 99. N 14. Pp. 6602-6607.

16. Ge X., Burner D.M., Xu J., Phillips G.C., Sivakumar G. Bioetahnol production from dedicated energy crops and residues in Arkansas, USA // Biotechnology Journal. 2011. Vol. 6. N 1. Pp. 66-73.

17. Gaveau D.L.A., Balzter H., Plummer S. Forest woody biomass classification with satellite-based radar coherence over $900000 \mathrm{~km}^{2}$ in Central Siberia // Forest Ecology and Management. 2003. Vol. 174. N 1-3. Pp. 65-75.

18. Голязимова О.В. Механическая активация ферментативного гидролиза целлюлозы и лигноцеллюлозных материалов: дис. ... канд. хим. наук. Новосибирск, 2010. 164 с.

19. Синицын А.П., Гусаков А.В., Черноглазов В.М. Биоконверсия лигноцеллюлозных материалов. М., 1995. $224 \mathrm{c}$.

20. Kumar P., Barrett D.M., Delwiche M.J., Stroeve P. Methods for pretreatment of lignocellulosic biomass for efficient hydrolysis and biofuel production // Industrial and Engineering Chemistry Research. 2009. Vol. 48. N 8. Pp. 3713-3729.

21. Fang Z. Pretreatment techniques for biofuels and biorefineries. Berlin, 2013. 457 p.

22. Kumakura M., Kojima T., Kaetsu I. Pretreatment of lignocellulosic wastes by combination of irradiation and mechanical crushing // Biomass. 1982. Vol. 2. N 4. Pp. 299-308.

23. Chaturvedi V., Verma P. An overview of key pretreatment processes employed for bioconversion of lignocellulosic biomass into biofuels and value added products // 3 Biotech. 2013. Vol. 3. N 5. Pp. 415-431. 
24. Bychkov A.L., Lomovskii O.I. Mechanical treatment effect on the cellulolytic speciment activity // Russian Journal of Applied Chemistry. 2010. Vol. 83. N 6. Pp. 1106-1108.

25. Lomovsky O.I., Lomovsky I.O. Mechanochemically assisted extraction // Enhancing Extraction Processes in the Food Industry. London; New York, 2011. Pp. 61-398.

26. Boldyrev V.V. Mechanochemistry and mechanical activation // Materials Science Forum. 1996. Vol. 225. Pp. 511-520.

27. Politov A., Golyazimova O. Increasing the energy yield of mechanochemical transformations: selected case studies // Faraday Discussions. 2014. Vol. 170. Pp. 345-356.

28. Bychkov A.L., Korolev K.G., Lomovsky O.I. Obtaining mannanoligosaccharide preparations by means of the mechanoenzymatic hydrolysis of yeast biomass // Applied Biochemistry and Biotechnology. 2010. Vol. 162. Pp. 2008-2014.

29. Grigoryeva T.F., Barinova A.P., Ancharov A.I., Lyakhov N.Z. Mechanosynthesis of nanocomposites for chemical interaction with external reagent // Journal of Alloys and Compounds. 2007. Vol. 434-435. Pp. 540-541.

30. Григорьева Т.Ф., Баринова А.П., Ляхов Н.З. Механохимический синтез в металлических системах. Новосибирск, 2008. $312 \mathrm{c}$.

31. Аввакумов Е.Г. Механические методы активации химических процессов. Новосибирск, 1986. 303 с.

32. Boldyrev V.V. Hydrothermal reactions under mechanochemical action // Powder Technology. 2002. Vol. 122. Pp. 247-254.

33. Радциг В.А. Механохимия полимеров глазами метода ЭПР (обзор) // Химическая физика. 2004. Т. 23. № 10. C. $70-109$.

34. Simionescu C.I., Oprea C.V. Mecanochimia compusilor macromoleculari. Bucharest, 1967. 344 p.

35. Butyagin P.Yu. The role of interphases in in low temperature reactions of mechanochemical synthesis // Colloid journal of the Russian Academy of Sciences. 1997. Vol. 59. N 4. Pp. 460-467.

36. Avvakumov E., Senna M., Kosova M. Soft mechanochemical synthesis: a basis for new chemical technologies. Boston, 2001. $207 \mathrm{p}$.

37. Tanaka K. Solvent-free organic synthesis. Weinheim, 2006. 442 p.

38. Toda F. Organic solid-state reactions. Dordrecht, 2013. 275 p.

39. Toda F. Solid state organic chemistry: efficient reactions, remarkable yields, and stereoselectivity // Accounts of Chemical Research. 1995. Vol. 28. N 12. Pp. 480-486.

40. Xie J., Lin Y.-S., Shi X.-J., Zhu X.-Y., Su W.-K., Wang P. Mechanochemical-assisted extraction of flavonoids from bamboo (Phyllostachys edulis) leaves // Industrial Crops and Products. 2013. Vol. 43. Pp. 276-282.

41. Meullemiestre A., Breil C., Abert-Vian M., Chemat F. Microwave, ultrasound, thermal treatments, and bead milling as intensification techniques for extraction of lipids from oleaginous Yarrowia lipolytica yeast for a biojetfuel application // Bioresource Technology. 2016. Vol. 211. Pp. 190-199.

42. Xu W., Yu J., Feng W., Su W. Selective extraction of gardenia yellow and geniposide from Gardenia jasminoides by mechanochemistry // Molecules. 2016. Vol. 21. N 5. Article number 540. doi:10.3390/molecules21050540

43. Korolev K.G., Lomovskii O.I., Rozhanskaya O.A., Vasi'ev V.G. Mechanochemical preparation of water-soluble forms of triterpene acids // Chemistry of Natural Compounds. 2003. Vol. 39. Pp. 366-372.

44. Pankrushina N., Nikitina I., Chernjak E., Myz C., Shakhtshneider T., Boldyrev V. Solvent-free mechanochemical modification of Lappaconitine and Piroxicam // Materials and Manufacturing Processes. 2008. Vol. 23. N 6. Pp. 561-565.

45. Gama F.M., Mota M. Enzymatic hydrolysis of cellulose (I): relationship between kinetics and physico-chemical parameters // Biocatalysis and Biotransformation. 1997. Vol. 15. N 3. Pp. 221-236.

46. Yeh A.-I., Huang Y.-C., Hsin S. Effect of particle size on the rate of enzymatic hydrolysis of cellulose // Carbohydrate Polymers. 2010. Vol. 79. N 1. Pp. 192-199.

47. Rahikainen J., Mikander S., Marjamaa K., Tamminen T., Lappas A., Viikari L., Kruus K. Inhibition of enzymatic hydrolysis by residual lignins from softwood-study of enzyme binding and inactivation on lignin-rich surface // Biotechnology and Bioengineering. 2011. Vol. 108. N12. Pp. 2823-2834.

48. Singh R., Shukla A., Tiwari S., Srivastava M. A review on delignification of lignocellulosic biomass for enhancement of ethanol production potential // Renewable and Sustainable Energy Reviews. 2014. Vol. 32. Pp. 713-728.

49. Kumar R., Hu F., Hubbell C.A., Ragauskas A.J., Wyman C.E. Comparison of laboratory delignification methods, their selectivity, and impacts on physiochemical characteristics of cellulosic biomass // Bioresource Technology. 2013. Vol. 130. Pp. 372-381.

50. Cantarella M., Mucciante C., Cantarella L. Inactivating effects of lignin-derived compounds released during lignocellulosic biomass pretreatment on the endo-glucanase catalyzed hydrolysis of carboxymethylcellulose: a study in continuous stirred ultrafiltration-membrane reactor// Bioresource Technology. 2014. Vol. 156. Pp. 48-56.

51. Umikalsom M.S., Ariff A.B., Karim M.I.A. Saccharification of pretreated oil palm empty fruit bunch fiber using cellulase of Chaetomium globosum // Journal of Agricultural and Food Chemistry. 1998. Vol. 46. N 8. Pp. 3359-3364.

52. Hames B.R., Thomas S.R., Sluiter A.D., Rapid biomass analysis: new tools for compositional analysis of corn stover feedstocks and process intermediates from ethanol production // Applied Biochemistry and Biotechnology. 2003. Vol. 105-108. Pp. 5-16.

53. Bychkov A.L., Ryabchikova E.I., Korolev K.G., Lomovsky O.I. Ultrastructural changes of cell walls under intense mechanical treatment of selective plant raw material // Biomass and Bioenergy. 2012. Vol. 47. Pp. 260-267.

54. Голязимова О.В., Политов А.А., Ломовский О.И. Увеличение эффективности измельчения лигноцеллюлозного растительного сырья с помощью химической обработки // Химия растительного сырья. 2009. №2. С. 53-57. 
55. Голязимова О.В., Политов А.А., Ломовский О.И. Механическая активация ферментативного гидролиза лигноцеллюлозы // Химия растительного сырья. 2009. № 2. С. 59-63.

56. Hall M., Bansal P., Lee J.H., Realff M.J., Bommarius A.S. Cellulose crystallinity - a key predictor of the enzymatic hydrolysis rate // FEBS Journal. 2010. Vol. 277. N 6. Pp. 1571-1582.

57. Синицын А.П., Ковалев Г.В., Месса-Манреса С.Р. Сравнительное изучение влияния различных видов предобработки на скорость ферментативного гидролиза природных целлюлозосодержащих материалов // Химия древесины. 1984. № 5. С. 60-71.

58. Yoshida M., Liu Y., Uchida S., Kawarada K., Ukagami Y., Ichinose H., Kaneko S., Fukuda K. Effects of cellulose crystallinity, hemicellulose, and lignin on the enzymatic hydrolysis of Miscanthus sinensis to monosaccharides // Bioscience, Biotechnology and Biochemistry. 2008. Vol. 72. N3. Pp. 805-810.

59. Hermans P.H., Weidinger A. On recrystallization of amorphous cellulose // Journal of American Chemical Society. 1946. Vol. 68. Pp. 2547-2552.

60. Yakunin N.A., Zavadskii A.E., Yakunina E.N., Moryganov A.P. Structural inhomogenity in cotton cellulose upon its interaction with water // Polymer Science. Series A. 2010. Vol. 52. N 2. Pp. 134-138.

61. Iyer P.B., Sreenivasan S., Chidambareswaran P.K., Patil N.B. Recrystallization of cellulose // Textile Research Journal. 1984. Vol. 54. N 11. Pp. 732-735.

62. Nakamura K., Hatakeyama T., Hatakeyama H. Studies of bound water of cellulose by differential scaning calorimetry // Textile Research Journal. 1981. Vol. 72. N 9. Pp. 607-613.

63. Ouajai S., Shanks R.A. Solvent and enzyme induced recrystallization of mechanically degraded hemp cellulose // Cellulose. 2006. Vol. 13. Pp. 31-44.

64. Paes S.S., Sun S., MacNaughtan W., Ibbett R., Ganster J., Foster T.J., Mitchell J.R. The glass transition and crystallization of ball milled cellulose // Cellulose. 2010. Vol. 17. Pp. 693-709.

65. Bertran M.S., Dale B.E. Enzymatic hydrolysis and recrystallization behavior of initially amorphous cellulose // Biotechnology and Bioengineering. 1985. Vol. 27. Pp. 177-181.

66. Wormald P., Wickholm K., Larsson P.T., Iversen T. Conversion between ordered and disordered cellulose. Effects of mechanical treatment followed by cyclic wetting and drying // Cellulose. 1996. Vol. 3. Pp. 141-152.

67. Liang X.H., Gu L.Z., Ding E.Y. Recrystallization behavior of cellulose and lignocellulose from Pinus massoniana // Wood Science and Technology. 1993. Vol. 27. N 6. Pp. 461-467.

68. Orlov D.V., Bychkov A.L., Lomovsky I.O. Effect of the lignocellulose matrix on the stability of quercetin under mechanical action // VIII International Conference of Mechanochemistry and Mechanical Alloying, Crakow, 2014. P. 43

69. Орлов Д.В., Ломовский И.О., Ломовский О.И. Устойчивость кверцетина к механическому воздействию в индивидуальном виде и в присутствии полимеров лигноцеллюлозной матрицы // II Всероссийская конференция «Горячие точки химии твердого тела: механизмы твердофазных процессов», Новосибирск, 2015. С. 36.

70. Zhou C., Liu G., Wang X., Qi C. Co-combustion of bituminous coal and biomass fuel blends: Thermochemical characterization, potential utilization and environmental advantage // Bioresource Technology. 2016. Vol. 218. Pp. 418-427.

71. Patent 4706903 (USA). Apparatus for the hydrolysis and disintegration of lignocellulosic / D.L. Brink, M.M. Merrimam, D.A. Mixxon / 17.11.1987.

72. Patent 5366558 (USA) Method of treating biomass material / D.L. Brink / 22.11.1994.

73. Akhtar M. Biomechanical pulping of aspen wood chips with three strains of Ceriporiopsis subvermispora // Holzforschung. 1994. Vol. 48. Pp. 199-202.

74. Zhao H., Kwak J.H., Wang Y., Franz J.A., White J.M., Holladay J.E. Effects of crystallinity on dilute acid hydrolysis of cellulose by cellulose ball-milling study // Energy \& Fuels. 2006. Vol. 20. Pp. 807-811.

75. Бурдуков А.П., Попов В.А., Чернецкий М.Ю., Дектерев А.А., Ломовский О.И., Бычков А.Л. Использование мелкодисперсного лигноцеллюлозного сырья в качестве твердого топлива // Ползуновский вестник. 2013. № 4/3. C. 16-27.

76. Piriou B., Vaitilingom G., Veyssiere B., Cuq B., Rouau X. Potential direct use of solid biomass in internal combustion engines // Progress in Energy and Combustion Science. 2013. Vol. 39. Pp. 169-188.

77. Siyi L., Bo X., Zhiquan H., Shiming L., Maoyun H. Experimental study on combustion of biomass micron fuel (BMF) in cyclone furnace // Energy Conversion and Management. 2010. Vol. 51. Pp. 2098-2102.

78. Бурдуков А.П., Попов В.И., Юсупов Т.С., Ломовский О.И. Влияние механохимической активации на горение углей в факеле // Химия в интересах устойчивого развития. 2009. Т. 17. № 5. С. 471-478.

79. Бурдуков А.П., Попов В.И., Фалеев В.А., Юсупов Т.С. Использование механоактивированных углей микропомола в энергетике // Ползуновский вестник. 2010. № 1. С. 93-98.

80. Юсупов Т.С., Шумская Л.Г., Бурдуков А.П. Химическая деминерализация углей разных стадий метаморфизма // Физико-технические проблемы разработки полезных ископаемых. 2009. №4. С. 111-116.

81. Юсупов Т.С., Бурдуков А.П. Влияние метаморфизма на измельчаемость углей при ударных воздействиях // VIII Всероссийская конференция с международным участием «Горение твердого топлива». Новосибирск, 2012. C. 112.1-112.3.

82. Luo S., Liu C., Xiao B., Xiao L. A novel biomass pulverization technology // Renewable Energy. 2011. Vol. 36. Pp. 578-582.

83. Repellin V., Govin A., Rolland M., Guyonnet R. Energy requirement for fine grinding of torrefied wood // Biomass and Bioenergy. 2010. Vol. 34. Pp. 923-930. 
84. Phanphanich M., Mani S. Impact of torrefaction on the grindability and fuel characteristics of forest biomass // Bioresource Technology. 2011. Vol. 102. Pp. 1246-1253.

85. Grethlein H.E., Converse A.O. Common aspects of acid prehydrolysis and steam explosion for preheating wood // Bioresource Technology. 1991. Vol. 36. N 2. Pp. 77-82.

86. Kenealy W., Klungness J., Tshabalala M. Modification of lignocellulosic materials by laccase // 2003 TAPPI Fall Technical Conference: Engineering, Pulping \& PCE\&I. Atlanta, 2003. P. 9

87. Клесов А.А., Синицын А.П. Ферментативный гидролиз целлюлозы. IV. Влияние физико-химических и структурных факторов субстрата на эффективность ферментативного гидролиза // Биоорганическая химия. 1981. T. 7. № 12. C. 1801-1812.

88. Namazi A.B., Jia C.Q., Allen D.G. Production and characterization of lignocellulosic biomass-derived activated carbon // Water Science \& Technology. 2010. Vol. 62. N 11. Pp. 2637-2646.

89. Horstmann B.J., Kennedy C.N., Chase H.A. Adsorption of proteins on Sepharose affinity adsorbents of varying particle size // Journal of Chromatography. 1986. Vol. 361. Pp. 179-190.

90. Wiman M., Dienes D., Hansen M.A.T., Van Der Meulen T., Zacchi G., Lidén G. Cellulose accessibility determines the rate of enzymatic hydrolysis of steam-pretreated spruce // Bioresource Technology. 2012. Vol. 126. Pp. 208-215.

91. Patent 7709042 (USA). Process for producing a pretreated feedstock / P. Foody / 4.05.2010.

92. Patent 5114488 (USA). Extrusion method and apparatus for acid treatment of cellulosic materials / G.R. Huber / 19.05.1992.

93. Patent 101085994 (China). Ferment method of producing fuel ethanol using stalk material / B. Zhang / 12.12.2007.

94. Патент № 2514408 (РФ). Способ ферментативного осахаривания лигноцеллюлозных материалов / А.Л. Бычков, О.И. Ломовский / 27.04.2014.

95. Akhtar M., Lentz M.J., Horn E.G. Biomechanical pulping: a mill-scale evaluation // Resources. Conservation and Recycling. 2010. Vol. 28. Pp. 241-252.

96. Masarin F., Pavan P.C., Vicentim M.P., Souza-Cruz P.B., Loguercio-Leite C., Ferraz A. Laboratory and mill scale evaluation of biopulping of Eucalyptus grandis Hill ex Maiden with Phanerochaete chrysosporium RP-78 under nonaseptic conditions // Holzforschung. 2009. Vol. 63. Pp. 259-263.

97. Lin Z., Huang H., Zhang H., Zhang L., Yan L., Chen J. Ball milling pretreatment of corn stover for enchancing the efficiency of enzymatic hydrolysis // Applied Biochemistry and Biotechnology. 2010. Vol. 162. Pp. 1872-1880.

98. Hilgert J., Meine N., Rinaldi R., Schüth F. Mechanocatalytic depolymerization of cellulose combined with hydrogenolysis as a highly efficient pathway to sugar alcohost // Energy \& Environmental Science. 2013. Vol. 6. Pp. 92-96.

99. Millett M.A., Effland M.J., Caulfield D.F. Influence of fine grinding on the hydrolysis of cellulosic materials - acid vs. enzymatic // Hydrolysis of cellulose: mechanisms of enzymatic and acid catalysis. American Chemical Society Advances in Chemistry. Series 181. Washington, 1979. Pp. 71-89.

100. Silva G.G., Couturier M., Berrin J.-G., Buleon A., Rouau X. Effects of grinding processes on enzymatic degradation of wheat straw // Bioresource Technology. 2012. Vol. 103. Pp. 192-200.

101. Alekseeva O.V., Rozhkova O.V., Prusov A.N. Effect of the conditions of mechanical treatment on the reactivity of cellulose // Fibre Chemistry. 1997. Vol. 29. N 2. Pp. 103-105.

102. Prusov A.N., Zheleznov K.N., Alekseeva O.V., Padokhin V.A., Rozhkova O.V. The effect of mechanical treatment on colloidal and chemical properties and reactivity of powdered cellulose // Colloidal Journal. 2002. Vol. 64 . N 5. Pp. 601-604.

103. Kokko L., Tolvanen H., Hamalainen K., Raiko R. Comparing the energy required for fine grinding torrefied and fast heat treated pine // Biomass and Bioenergy. 2012. Vol. 42. Pp. 219-223.

Поступило в редакциюю 13 октября 2016 г.

После переработки 7 декабря 2016 г. 


\section{Bychkov A.L. *, Lomovsky O.I. RECENT ADVANCES IN MECHANOCHEMICAL PROCESSING OF PLANT RAW} MATERIALS

Institute of Solid State Chemistry and Mechanochemistry SB RAS, ul. Kutateladze, 18, Novosibirsk, 630128 (Russia), e-mail: bychkov.a.l@gmail.com

Overview of current data published on the subject of mechanically activated processes of processing plant raw materials is carried out in the work. Examples of physical and chemical processes occurring during mechanical treatment of individual substances and plant raw materials are listed. Mechanochemical treatment allows to increase the reactivity of the substances included in the plant raw material by increasing the specific surface area (such as the area «suitable» to interact with the reagents, enzymes), reducing cellulose crystallinity and the overall disordering supramolecular structure of the cell walls. Mechanochemical treatment of plant raw materials together with enzymes can produce of high reactive composites in which reagents are equally distributed over the substrate by no diffusive way (by mechanically way). Subsequent chemical reactions with participation of these composites proceed more efficiently due reducing the diffusion paths and improve the stability of target substances or enzymes (for biotechnological processes), and extraction of reaction products occurs more completely. The economic efficiency is often a limiting factor in implementation of new technologies, including one or more stages of crushing or mechanical activation, determined by the cost of mechanical treatment.

Keywords: plant raw materials, mechanochemistry, structure, disordering, defectiveness, processing, technology.

The study was performed at the expense of the grant of the Russian Scientific Foundation (grant № 16-13-10200).

\section{References}

1. Kuznetsov B.N., Chesnokov N.V., Yatsenkova O.V., Sharypov V.I. Russian Chemical Bulletin, 2013, vol. 62, no. 7, pp. 1493-1502.

2. Kushnir E.Y., Autlov S.A., Bazarnova N.G. Russian Journal of Bioorganic Chemistry, 2015, vol. 41, no. 7, pp. 713-718.

3. Mikhailenko M.A., Shakhtshneider T.P., Drebushchak V.A., SkvortsovaG.P., Boldyrev V.V. Chemistry of Natural Compounds, 2011, vol. 47, no. 2, pp. 229-233.

4. Seliutina O.Iu., Poliakov N.E., Meteleva E.S., Dushkin A.V. Khimiia v interesakh ustoichivogo razvitiia, 2015, vol. 23, no. 5, pp. 549-560. (in Russ.).

5. Manaenkov O.V., Filatova A.E., Makeeva O.Y., Kislitsa O.V., Doluda V.Yu., Sidorov A.I., Matveeva V.G., Sul'man E.M. Catalysis in Industry. 2014. Vol. 6. N2. Pp. 150-157.

6. Bazarnova N.G., Markin V.I., Katrakov I.B., Kolosov P.V., Cheprasova M.Y., Kalyuta E.V. Russian Journal of General Chemistry, 2015, vol. 82, no. 5, pp. 947-954.

7. Shapolova E.G., Lomovsky O.I. Russian Journal of Bioorganic Chemistry, 2013, vol. 39, no. 7, pp. 765-770.

8. Galbe M., Zacchi G. Applied Microbiology and Biotechnology, 2002, vol. 59, pp. 618-628.

9. Lynd L.R., Weimer P.J., Zyl W.H., Pretorius I.S. Microbiology and Molecular Biology Reviews, 2002, vol. 66, no. 3, pp. 506-577.

10. Zheng Y., Pan Z., Zhang R. International Journal of Agricultural and Biological Engineering, 2009, vol. 2, no. 3, pp. 51-68.

11. Taherzadeh M.J., Karimi K. International Journal of Molecular Sciences, 2008, vol. 9, pp. 1621-1651.

12. Bai F.W., Anderson W.A., Moo-Young M. Biotechnology Advances, 2008, vol. 26, no. 1, pp. 89-105.

13. Skiba E.A., Budaeva V.D., Makarova E.I., Pavlov I.N., Zolotukhin V.N., Sakovich G.V. Vestnik Kazanskogo tekhnologicheskogo universiteta, 2013, vol. 16, no. 22, pp. 202-205. (in Russ.).

14. Makarova E.I., Budaeva V.V., Skiba E.A., Sakovich G.V. Catalysis in Industry, 2014, vol. 6, no. 1, pp. 67-71.

15. Sørensen A., Teller P.J., Hilstrøm T., Ahring B.K. Bioresource Technology, 2008, vol. 99, no. 14, pp. 6602-6607.

16. Ge X., Burner D.M., Xu J., Phillips G.C., Sivakumar G. Biotechnology Journal, 2011, vol. 6, no. 1, pp. 66-73.

17. Gaveau D.L.A., Balzter H., Plummer S. Forest Ecology and Management, 2003, vol. 174, no. 1-3, pp. 65-75.

18. Goliazimova O.V. Mekhanicheskaia aktivatsiia fermentativnogo gidroliza tselliulozy $i$ lignotselliuloznykh materialov: dis. ... kand. khim. nauk. [Mechanical activation of enzymatic hydrolysis of cellulose and lignocellulosic materials: dis. ... cand. Chem. Sciences]. Novosibirsk, 2010, 164 p. (in Russ.).

19. Sinitsyn A.P., Gusakov A.V., Chernoglazov V.M. Biokonversiia lignotselliuloznykh materialov. [Bioconversion of lignocellulosic materials]. Moscow, 1995, 224 p. (in Russ.).

20. Kumar P., Barrett D.M., Delwiche M.J., Stroeve P. Industrial and Engineering Chemistry Research, 2009, vol. 48, no. 8, pp. 3713-3729.

21. Fang Z. Pretreatment techniques for biofuels and biorefineries. Berlin, 2013, 457 p.

22. Kumakura M., Kojima T., Kaetsu I. Biomass., 1982, vol. 2, no. 4, pp. 299-308.

23. Chaturvedi V., Verma P. 3 Biotech., 2013, vol. 3, no. 5, pp. 415-431.

24. Bychkov A.L., Lomovskii O.I. Russian Journal of Applied Chemistry, 2010, vol. 83, no. 6, pp. 1106-1108.

25. Lomovsky O.I., Lomovsky I.O. Enhancing Extraction Processes in the Food Industry, London, New York, 2011, pp. 61-398.

26. Boldyrev V.V. Materials Science Forum, 1996, vol. 225, pp. 511-520.

27. Politov A., Golyazimova O. Faraday Discussions, 2014, vol. 170, pp. 345-356.

28. Bychkov A.L., Korolev K.G., Lomovsky O.I. Applied Biochemistry and Biotechnology, 2010, vol. 162, pp. $2008-2014$.

\footnotetext{
* Corresponding author.
} 
29. Grigoryeva T.F., Barinova A.P., Ancharov A.I., Lyakhov N.Z. Journal of Alloys and Compounds, 2007, vol. 434435 , pp. 540-541.

30. Grigor'eva T.F., Barinova A.P., Liakhov N.Z. Mekhanokhimicheskii sintez $v$ metallicheskikh sistemakh. [Mechanochemical synthesis in metallic systems]. Novosibirsk, 2008, 312 p. (in Russ.).

31. Avvakumov E.G. Mekhanicheskie metody aktivatsii khimicheskikh protsessov. [Mechanical methods of activation of chemical processes]. Novosibirsk, 1986, 303 p. (in Russ.).

32. Boldyrev V.V. Powder Technology, 2002, vol. 122, pp. 247-254.

33. Radtsig V.A. Khimicheskaia fizika, 2004, vol. 23, no. 10, pp. 70-109. (in Russ.).

34. Simionescu C.I., Oprea C.V. Mecanochimia compusilor macromoleculari, Bucharest, 1967, 344 p.

35. Butyagin P.Yu. Colloid journal of the Russian Academy of Sciences, 1997, vol. 59, no. 4, pp. 460-467.

36. Avvakumov E., Senna M., Kosova M. Soft mechanochemical synthesis: a basis for new chemical technologies, Boston, 2001, $207 \mathrm{p}$.

37. Tanaka K. Solvent-free organic synthesis, Weinheim, 2006, 442 p.

38. Toda F. Organic solid-state reactions, Dordrecht, 2013, $275 \mathrm{p}$.

39. Toda F. Accounts of Chemical Research, 1995, vol. 28, no. 12, pp. 480-486.

40. Xie J., Lin Y.-S., Shi X.-J., Zhu X.-Y., Su W.-K., Wang P. Industrial Crops and Products, 2013, vol. 43, pp. $276-282$.

41. Meullemiestre A., Breil C., Abert-Vian M., Chemat F. Bioresource Technology, 2016, vol. 211, pp. 190-199.

42. Xu W., Yu J., Feng W., Su W. Molecules, 2016, vol. 21, no. 5, article number 540, doi:10.3390/molecules21050540

43. Korolev, K.G.; Lomovskii, O.I.; Rozhanskaya, O.A.; Vasi'ev, V.G. Chemistry of Natural Compounds, 2003, vol. 39, pp. 366-372.

44. Pankrushina N., Nikitina I., Chernjak E., Myz C., Shakhtshneider T., Boldyrev V. Materials and Manufacturing Processes, 2008, vol. 23, no. 6, pp. 561-565.

45. Gama F.M., Mota M. Biocatalysis and Biotransformation, 1997, vol. 15, no. 3, pp. 221-236.

46. Yeh A.-I., Huang Y.-C., Hsin S. Carbohydrate Polymers, 2010, vol. 79, no. 1, pp. 192-199.

47. Rahikainen J., Mikander S., Marjamaa K., Tamminen T., Lappas A., Viikari L., Kruus K. Biotechnology and Bioengineering, 2011, vol. 108, no. 12, pp. 2823-2834.

48. Singh R., Shukla A., Tiwari S., Srivastava M. Renewable and Sustainable Energy Reviews, 2014, vol. 32, pp. 713-728.

49. Kumar R., Hu F., Hubbell C.A., Ragauskas A.J., Wyman C.E. Bioresource Technology, 2013, vol. 130, pp. $372-381$.

50. Cantarella M., Mucciante C., Cantarella L. Bioresource Technology, 2014, vol. 156, pp. 48-56.

51. Umikalsom M.S., Ariff A.B., Karim M.I.A. Journal of Agricultural and Food Chemistry, 1998, vol. 46, no. 8, pp. 3359-3364.

52. Hames B.R., Thomas S.R., Sluiter A.D. Applied Biochemistry and Biotechnology, 2003, vol. 105-108, pp. 5-16.

53. Bychkov A.L., Ryabchikova E.I., Korolev K.G., Lomovsky O.I. Biomass and Bioenergy, 2012, vol. 47, pp. $260-267$.

54. Goliazimova O.V., Politov A.A., Lomovskii O.I. Khimiia rastitel'nogo syr'ia, 2009, no. 2, pp. 53-57. (in Russ.).

55. Goliazimova O.V., Politov A.A., Lomovskii O.I. Khimiia rastitel'nogo syr'ia, 2009, no. 2, pp. 59-63. (in Russ.).

56. Hall M., Bansal P., Lee J.H., Realff M.J., Bommarius A.S. FEBS Journal, 2010, vol. 277, no. 6, pp. 1571-1582.

57. Sinitsyn A.P., Kovalev G.V., Messa-Manresa S.R. Khimiia drevesiny, 1984, no. 5, pp. 60-71. (in Russ.).

58. Yoshida M., Liu Y., Uchida S., Kawarada K., Ukagami Y., Ichinose H., Kaneko S., Fukuda K. Bioscience, Biotechnology and Biochemistry, 2008, vol. 72, no. 3, pp. 805-810.

59. Hermans P.H., Weidinger A. Journal of American Chemical Society, 1946, vol. 68, pp. 2547-2552.

60. Yakunin N.A., Zavadskii A.E., Yakunina E.N., Moryganov A.P. Polymer Science. Series A, 2010, vol. 52, no. 2, pp. 134-138.

61. Iyer P.B., Sreenivasan S., Chidambareswaran P.K., Patil N.B. Textile Research Journal, 1984, vol. 54, no. 11, pp. $732-735$.

62. Nakamura K., Hatakeyama T., Hatakeyama H. Textile Research Journal, 1981, vol. 72, no. 9, pp. 607-613.

63. Ouajai S., Shanks R.A. Cellulose, 2006, vol. 13, pp. 31-44.

64. Paes S.S., Sun S., MacNaughtan W., Ibbett R., Ganster J., Foster T.J., Mitchell J.R. Cellulose, 2010, vol. 17, pp. 693-709.

65. Bertran M.S., Dale B.E. Biotechnology and Bioengineering, 1985, vol. 27, pp. 177-181.

66. Wormald P., Wickholm K., Larsson P.T., Iversen T. Cellulose, 1996, vol. 3, pp. 141-152.

67. Liang X.H., Gu L.Z., Ding E.Y. Wood Science and Technology, 1993, vol. 27, no. 6, pp. 461-467.

68. Orlov D.V., Bychkov A.L., Lomovsky I.O. VIII International Conference of Mechanochemistry and Mechanical Alloying, Crakow, 2014, p. 43.

69. Orlov D.V., Lomovskii I.O., Lomovskii O.I. II Vserossiiskaia konferentsiia «Goriachie tochki khimii tverdogo tela: mekhanizmy tverdofaznykh protsessov». [II All-Russian Conference "Hot Spots of Solid State Chemistry: Mechanisms of Solid-Phase Processes"]. Novosibirsk, 2015, p. 36. (in Russ.).

70. Zhou C., Liu G., Wang X., Qi C. Bioresource Technology, 2016, vol. 218, pp. 418-427.

71. Patent 4706903 (USA). 17.11.1987.

72. Patent 5366558 (USA). 22.11.1994.

73. Akhtar M. Holzforschung, 1994, vol. 48, pp. 199-202.

74. Zhao H., Kwak J.H., Wang Y., Franz J.A., White J.M., Holladay J.E. Energy \& Fuels, 2006, vol. 20, pp. 807-811.

75. Burdukov A.P., Popov V.A., Chernetskii M.Iu., Dekterev A.A., Lomovskii O.I., Bychkov A.L. Polzunovskii vestnik, 2013, no. 4/3, pp. 16-27. (in Russ.).

76. Piriou B., Vaitilingom G., Veyssiere B., Cuq B., Rouau X. Progress in Energy and Combustion Science, 2013, vol. 39, pp. 169-188. 
77. Siyi L., Bo X., Zhiquan H., Shiming L., Maoyun H. Energy Conversion and Management, 2010, vol. 51, pp. $2098-2102$.

78. Burdukov A.P., Popov V.I., Iusupov T.S., Lomovskii O.I. Khimiia v interesakh ustoichivogo razvitiia, 2009, vol. 17, no. 5, pp. 471-478. (in Russ.).

79. Burdukov A.P., Popov V.I., Faleev V.A., Iusupov T.S. Polzunovskii vestnik, 2010, no. 1, pp. 93-98. (in Russ.).

80. Iusupov T.S., Shumskaia L.G., Burdukov A.P. Fiziko-tekhnicheskie problemy razrabotki poleznykh iskopaemykh, 2009, no. 4, pp. 111-116. (in Russ.).

81. Iusupov T.S., Burdukov A.P. VIII Vserossiiskaia konferentsiia s mezhdunarodnym uchastiem «Gorenie tverdogo topliva». [VIII All-Russian Conference with International Participation "Combustion of Solid Fuel"]. Novosibirsk, 2012, pp. 112.1-112.3. (in Russ.).

82. Luo S., Liu C., Xiao B., Xiao L. Renewable Energy, 2011, vol. 36, pp. 578-582.

83. Repellin V., Govin A., Rolland M., Guyonnet R. Biomass and Bioenergy, 2010, vol. 34, pp. 923-930.

84. Phanphanich M., Mani S. Bioresource Technology, 2011, vol. 102, pp. 1246-1253.

85. Grethlein H.E., Converse A.O. Bioresource Technology, 1991, vol. 36, no. 2, pp. 77-82.

86. Kenealy W., Klungness J., Tshabalala M. 2003 TAPPI Fall Technical Conference: Engineering, Pulping \& PCE\&I. Atlanta, 2003, p. 9

87. Klesov A.A., Sinitsyn A.P. Bioorganicheskaia khimiia, 1981, vol. 7, no. 12, pp. 1801-1812. (in Russ.).

88. Namazi A.B., Jia C.Q., Allen D.G. Water Science \& Technology, 2010, vol. 62, no. 11, pp. 2637-2646.

89. Horstmann B.J., Kennedy C.N., Chase H.A. Journal of Chromatography, 1986, vol. 361, pp. 179-190.

90. Wiman M., Dienes D., Hansen M.A.T., Van Der Meulen T., Zacchi G., Lidén G. Bioresource Technology, 2012, vol. 126, pp. 208-215.

91. Patent 7709042 (USA). 4.05.2010.

92. Patent 5114488 (USA). 19.05.1992.

93. Patent 101085994 (China). 12.12.2007.

94. Patent 2514408 (RU). 27.04.2014. (in Russ.).

95. Akhtar M., Lentz M.J., Horn E.G. Resources. Conservation and Recycling, 2010, vol. 28, pp. 241-252.

96. Masarin F., Pavan P.C., Vicentim M.P., Souza-Cruz P.B., Loguercio-Leite C., Ferraz A. Holzforschung, 2009 , vol. 63, pp. 259-263.

97. Lin Z., Huang H., Zhang H., Zhang L., Yan L., Chen J. Applied Biochemistry and Biotechnology, 2010, vol. 162, pp. $1872-1880$.

98. Hilgert J., Meine N., Rinaldi R., Schüth F. Energy \& Environmental Science, 2013, vol. 6, pp. 92-96.

99. Millett M.A., Effland M.J., Caulfield D.F. Hydrolysis of cellulose: mechanisms of enzymatic and acid catalysis. American Chemical Society Advances in Chemistry, Series 181, Washington, 1979, pp. 71-89.

100. Silva G.G., Couturier M., Berrin J.-G., Buleon A., Rouau X. Bioresource Technology, 2012, vol. 103, pp. $192-200$.

101. Alekseeva O.V., Rozhkova O.V., Prusov A.N. Fibre Chemistry, 1997, vol. 29, no. 2, pp. 103-105.

102. Prusov A.N., Zheleznov K.N., Alekseeva O.V., Padokhin V.A., Rozhkova O.V. Colloidal Journal, 2002, vol. 64, no. 5, pp. 601-604.

103. Kokko L., Tolvanen H., Hamalainen K., Raiko R. Biomass and Bioenergy, 2012, vol. 42, pp. 219-223.

Received October 13, 2016

Revised December 7, 2016 
